\title{
Implementasi Gerakan Manusia Pada Animasi 3D Dengan Menggunakan Menggunakan Metode Pose to pose
}

\author{
Victor Waeo, Arie S.M. Lumenta, Brave A. Sugiarso \\ Teknik Informatika Universitas Sam Ratulangi. Manado, Indonesia \\ waeovictor@gmail.com,al@unsrat.ac.id, brave@unsrat.ac.id
}

\begin{abstract}
Abstrak - Sebagai bagian dari tahap produksi film animasi 3D, proses animating merupakan proses yang berperan besar untuk menghasilkan film animasi 3D yang baik. Permasalahan sering dihadapi dalam proses animating adalah kualitas gerak animasi yang jauh dari kesan nyata dan halus, oleh karena itu cerita serta pesan yang pada film animasi 3D tersebut tidak tersampaikan dengan baik kepada penontonnya. Banyak ditemukan film animasi 3D seperti itu dikarenakan kurangnya pengalaman serta pemahaman akan metode dan prinsipprinsip dasar animasi.

Penelitian ini membahas tentang salah satu metode yang berkaitan dengan prinsip-prinsip dasar animasi, yaitu metode pose to pose. Pembahasan metode dilakukan dengan mengimplementasikan beberapa gerak dasar pada manusia pada animasi 3D dengan menggunakan objek figur 3D untuk memperagakan gerakan-gerakan dasar tersebut. Perancangan animasi dalam penelitian ini dilakukan melalui tiga tahapan yaitu pra produksi, produksi, dan pasca produksi serta menggunakan aplikasi Blender.

Penelitian ini berhasil mengimplementasikan gerakan manusia dalam bentuk animasi 3D. Diharapkan melalui penelitian ini dapat memperkenalkan metode pose to pose kepada para pembaca yang sedang mempelajari topik pembuatan animasi 3D serta dapat menghasilkan suatu film animasi 3D dengan kualitas gerakan yang baik.
\end{abstract}

Kata kunci: Animasi 3D, Pose to pose, Blender.

Abstract - As part of the production of $3 D$ animation film, the process of animating is a process that serves to produce good 3D animation film. The problems that often faced in animating process is the quality of motion animation away from the impression of real and smooth, therefore the story and the message on 3D animation film does not deliver well to the audience. Many found $3 D$ animation film like that because the lack of experience as well as the understanding about methods and the basic principles of animation.

This research discuss about one of the method which is related with basic animation principles namely pose to pose method. The method's discussion is done with implementation some motions basic in human, on the animated $3 D$ using the object $3 D$ figure to demonstrate basic movement. The animation in this study was conducted through three stages, namely pre-production, production, and post production by using Blender application.
Expected through this research, the writer are able to introduce pose to pose method to the readers who are studying the topic of $3 D$ animation as well as can produce a 3D animation film with a good quality of motion.

Key Words : 3D Animation, Pose to pose, Blender.

\section{PENDAHULUAN}

\section{A. Latar Belakang}

Proses animating adalah salah satu proses yang penting dalam produksi sebuah film animasi 3D, dalam hal ini adalah hasil akhir proses animating yang berupa rangkaian gerak animasi. Peran animator yang bekerja dibalik proses ini sangatlah dibutuhkan untuk menciptakan gerak animasi yang terlihat nyata karena kualitas suatu gerak animasi sangatlah mempengaruhi proses penyampaian cerita yang terkandung dalam sebuah film animasi 3D.

Dengan kata lain film animasi 3D dengan gerak animasi yang tidak nyata dan kaku akan dianggap tidak menarik peminatnya, sehingga cerita dan adegan yang ditampilkan tidak dapat ditangkap dengan baik oleh penontonnya.

Untuk dapat menghasilkan kualitas gerak animasi yang baik seorang animator sangat perlu untuk memahami prinsip-prinsip dasar dan metode yang digunakan dalam proses animating

Salah satu metode yang sudah lama dikenal dalam proses animating adalah metode Pose to pose. Berbeda dengan metode straight ahead yang dibuat secara satu demi satu frame, metode Pose to pose mendahulukan pembuatan beberapa pose penting yang mewakili suatu gerak animasi, dan dilanjutkan dengan pose yang menghasilkan efek gerak animasi itu sendiri. Kelebihan dari metode ini adalah waktu pengerjaan yang relatif lebih cepat, gerak animasi yang dihasilkan lebih terkonsep, kesalahan yang ditemukan dalam mengatur pose dapat dikoreksi dengan mudah.

Berdasarkan latar belakang tersebut penulis membuat skripsi dengan judul Implementasi Gerakan Manusia Pada Animasi 3D dengan Menggunakan Metode Pose to pose. 


\section{B. Rumusan Masalah}

Berdasarkan latar belakang yang telah diuraikan sebelumnya, maka rumusan masalah yang menjadi bahasan adalah:

- Bagaimana langkah kerja menggunakan metode pose to pose untuk menghasilkan gerak animasi yang terkesan nyata dan halus.

\section{Batasan Masalah}

Adapun Batasan masalah dalam penelitian ini adalah :

- $\quad$ Menggunakan aplikasi Blender sebagai perangkat lunak animasi

- Proses rigging menggunakan Human Metarig yang tersedia pada Blender

- Gerakan yang diimplementasikan adalah gerakan dasar yang dilakukan seperti lari, berjalan, dan melompat.

\section{Tujuan}

Tujuan yang akan dicapai dari penelitian ini adalah menghasilkan gerak animasi yang terkesan nyata dan halus, yang ditunjukkan pada sebuah video yang menampilkan gerakan-gerakan yang dilakukan manusia.

\section{E. Manfaat Penelitian}

Penelitian ini diharapkan dapat memperkenalkan metode pose to pose kepada pembaca yang sedang mempelajari topik pembuatan film animasi 3D, diharapkan juga pembaca dapat menerapkannya dalam membuat film animasi 3D dengan kualitas gerak animasi yang baik.

\section{LANDASAN TEORI}

\section{A. Animasi}

Definisi animasi sendiri berasal dari kata to animate yang berarti menggerakkan, menghidupkan. Misalkan sebuah benda yang mati, lalu digerakkan melalui perubahan sedikit demi sedikit dan teratur sehingga memberikan kesan hidup.

Djalle Zaharuddin mendefiniskan animasi sebagai proses penciptaan efek gerak atau efek perubahan bentuk yang terjadi selama beberapa waktu. Animasi juga merupakan suatu teknik menampilkan gambar berurut sedemikian rupa sehingga penonton merasakan adanya ilustrasi gerakan (motion) pada gambar yang ditampilkan. Definisi tersebut mengartikan bahwa benda-benda mati dapat 'dihidupkan'. Pengertian tersebut hanyalah merupakan istilah yang memiripkan, dalam arti tidak harus diterjemahkan secara denotatif, melainkan simbol yang menyatakan unsur kedekatan. ${ }^{[5]}$

\section{B. Animasi 3D}

Chris Broomhall menyatakan bahwa didalam komputer, 3D digambarkan sebagai sebuah gambar yang memiliki kedalaman. ${ }^{[9]}$

Menurut Aditya Animasi 3D adalah animasi yang berwujud 3D. Meskipun bukan dalam wujud 3D yang sebenarnya, yaitu bukan sebuah objek 3D yang dapat di sentuh dan di rasakan wujud fisiknya, namun dalam wujud 3D dalam layar kaca 2D (media layar TV, bioskop, komputer, proyektor, dan media sejenisnya). Animasi 3D selain memiliki kedua dimensi tersebut juga memiliki kedalaman (Z). Animasi 2D bersifat datar (flat), sedangkan animasi 3D memilki kedalaman (volume) bentuk. Animasi 3D dapat didefinisikan sebagai animasi yang dapat dilihat dari berbagai sudut pandang (point of view). ${ }^{[7]}$

C. Arcs

Dalam animasi, sistem pergerakan tubuh pada manusia, binatang, atau makhluk hidup lainnya bergerak mengikuti pola/jalur (maya) yang disebut Arcs. Hal ini memungkinkan mereka bergerak secara 'smooth' dan lebih realistik, karena pergerakan mereka mengikuti suatu pola yang berbentuk lengkung (termasuk lingkaran, elips, atau parabola). Pola gerak semacam inilah yang tidak dimiliki oleh sistem pergerakan mekanik/ robotik yang cenderung patah-patah.

\section{Blender}

Blender adalah perangkat kreasi 3D yang bersifat gratis dan open source. Blender medukung seluruh alur kerja 3D seperi modeling, rigging, animasi, simulasi, rendering, compositing dan motion tracking, bahkan pengeditan video dan pembuatan game. Blender sangat cocok digunakan oleh perseorangan maupun oleh studio kecil yang bermanfaat dalam proyek 3D. ${ }^{[10]}$

\section{E. Human (Meta-rig)}

Human (Meta-rig) adalah serangkaian bone yang terbentuk seperti struktur kerangka tubuh manusia. Human metarig terbentuk secara otomatis dengan adanya Rigify yang merupakan add on yang terdapat pada Blender. Dari pada melekatkan rig kedalam objek model figur, Human (Meta-rig) menghasilkan kumpulan controller berdasarkan bagian dari rig tersebut, controller yang dihasilkan tersebut nantinya akan digunakan untuk mengatur pose pada objek model figur.

\section{F. Tahap Perancangan Animasi}

Pembuatan sebuah film animasi melalui berbagai proses, dimulai dari penentuan konsep cerita dan pembuatan storyboard. Setelah konsep ditentukan 
proses selanjutnya adalah dengan proses pengambilan gambar yang dipecah menjadi beberapa komponen seperti modeling, rigging, animasi, dan lain sebagainya. Kerlow menyimpulkan bahwa agar hasil akhir dapat tercapai maka semua bagian dalam alur kerja tersebut haruslah saling berkaitan, alur tersebut dikenal dengan pipeline yang dibagi kedalam tiga tahap, yaitu pra produksi, produksi, dan pasca produksi seperti pada gambar 1. ${ }^{[2]}$

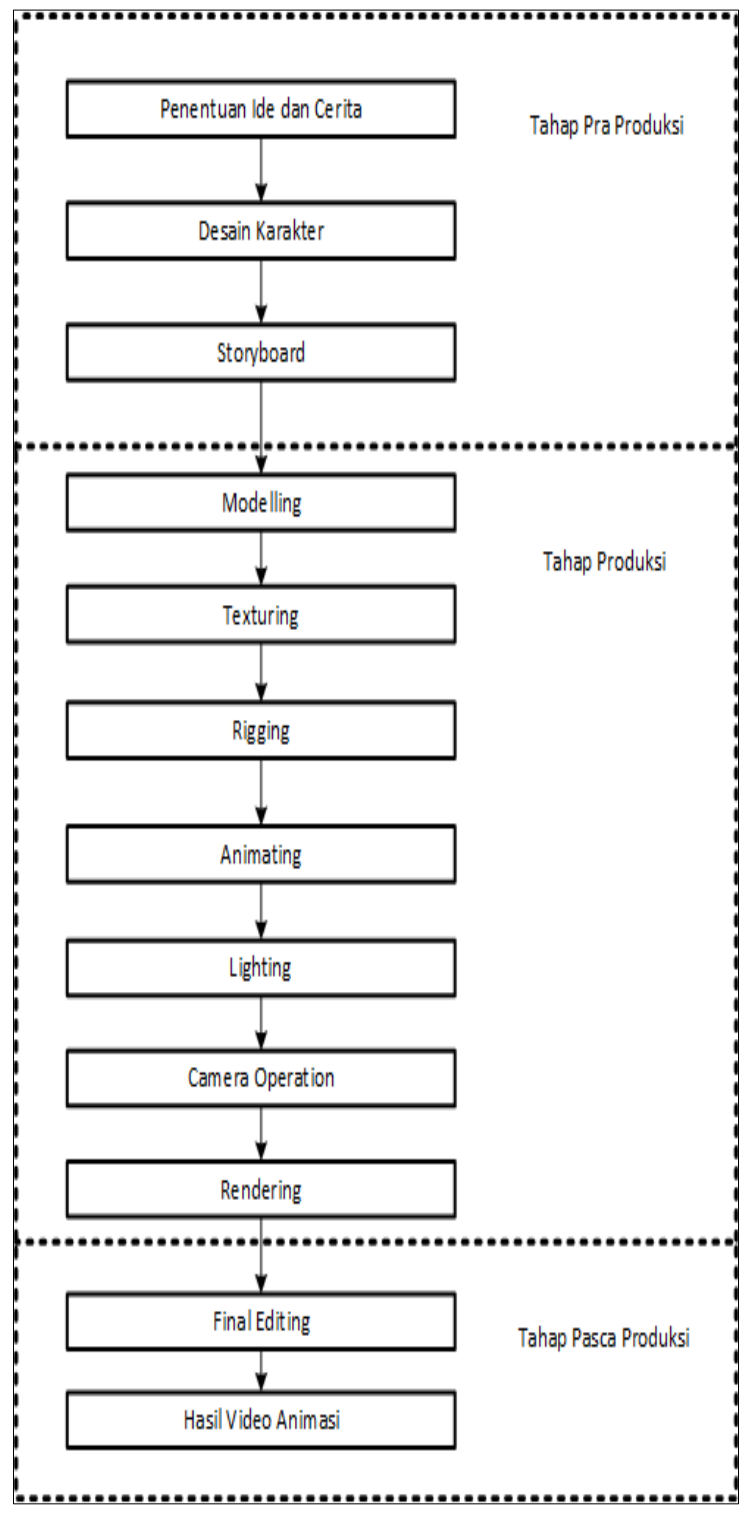

Gambar 1. Alur perancangan animasi 3D

\section{- Pra Produksi.}

Tahapan pra produksi adalah tahapan perencanaan, perancangan, serta penelitian pada keseluruhan proyek pembuatan animasi 3D, proses kerja yang ada dalam tahapan ini dapat berbeda sesuai dengan kebutuhan suatu proyek kerja.

- Produksi.

Pada tahap ini semua perencanaan yang dilakukan pada tahap pra produksi mulai dijalankan, semua materi yang dibuat pada tahap pra produksi dikumpulkan dan berikan kepada artist yang tepat untuk dikerjakan. Tahap ini merupakan tahap yang paling banyak memakan waktu dan seringkali muncul resiko dimana beberapa aset yang sudah jadi harus dibuat kembali.

\section{- Pasca Produksi.}

Adalah bagian akhir dalam proyek animasi $3 \mathrm{D}$, namun proses dalam pasca produksi bisa berbeda pada masing-masing studio animasi. Dalam industri hiburan tahap ini digunakan untuk untuk benar-benar membuat sebuah proyek benar-benar menonjol melalui efek dan koreksi warna.

\section{G. Gerakan Dasar Manusia}

Menurut Sukintaka, pada dasamya gerak dasar manusia secara umum terdiri atas tiga macam $\operatorname{gerak}^{[10]}$, yaitu:

\section{- Kemampuan Locomotor}

Kemampuan locomotor digunakan untuk memindahkan tubuh dari satu tempat ke tempat lain atau untuk mengangkat tubuh ke atas seperti lompat dan loncat. Kemampuan gerak lainnya adalah berjalan, berlari, skipping, melompat, meluncur dan lari seperti kuda berlari (gallop).

\section{- Kemampuan Non Locomotor}

Kemampuan non locomotor dilakukan di tempat. Tanpa ada ruang gerak yang memadai kemampuan non locomotor terdiri dari menekuk dan meregang, mendorong dan menarik, mengangkat dan menurunkan, melipat dan memutar, melingkar, melambungkan dan lainlain.

\section{- Kemampuan Manipulatif}

Kemampuan manipulatif dikembangkan ketika sudah menguasai macam-macam objek. Kemampuan manipulatif lebih banyak melibatkan tangan dan kaki, tetapi bagian lain dari tubuh kita juga dapat digunakan. Manipulasi objek jauh lebih unggul daripada koordinasi mata-kaki dan tangan-mata, yang mana cukup penting untuk 
berjalan (gerakan langkah) dalam ruang. Bentukbentuk kemampuan manipulatif terdiri dari:

\section{METODOLOGI PENGEMBANGAN}

A. Tahap Pra Produksi

\section{- Penentuan Ide dan Cerita}

Dalam penentuan ide disepakati bahwa video animasi akan menampilkan sebuah objek figur yang memperagakan gerakan-gerakan pada manusia, gerakan yang sudah ditentukan antara lain lompat gawang, gerakan melompati sebuah kotak, gerakan naik dan turun tangga, berjalan dan duduk, parkour. Video animasi juga akan menampilkan perbandingan antara animasi yang tidak menggunakan metode pose to pose dengan animasi yang dibuat penulis, perbandingan lainnya adalah dengan gerakan yang akan diperagakan oleh actor atau gerakan sebenarnya.

\section{- Desain Karakter}

Gambar 2 adalah hasil desain figur yang akan dibuat untuk memperagakan gerakan manusia.

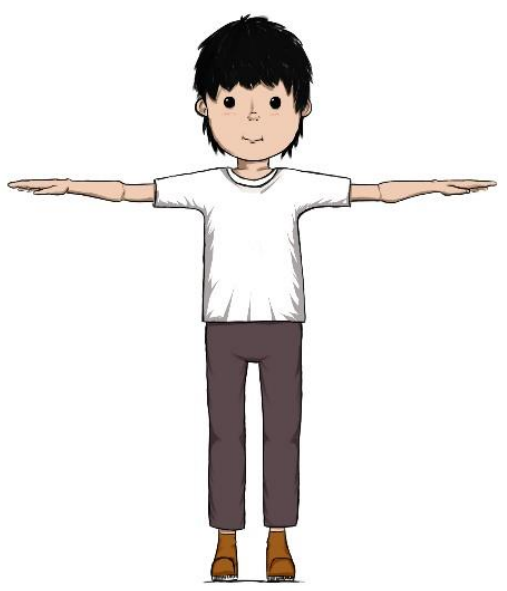

Gambar 2. Desain Figur

- $\quad$ Storyboard

Setelah ide cerita dan konsep desain karakter sudah dibuat, penulis merancang alur cerita dalam bentuk storyboard seperti yang dapat dilihat pada gambar 3. Tujuan lain dibuatnya storyboard agar mempermudah penulis dalam melakukan pengambilan sudut pandang pada proses camera operation.

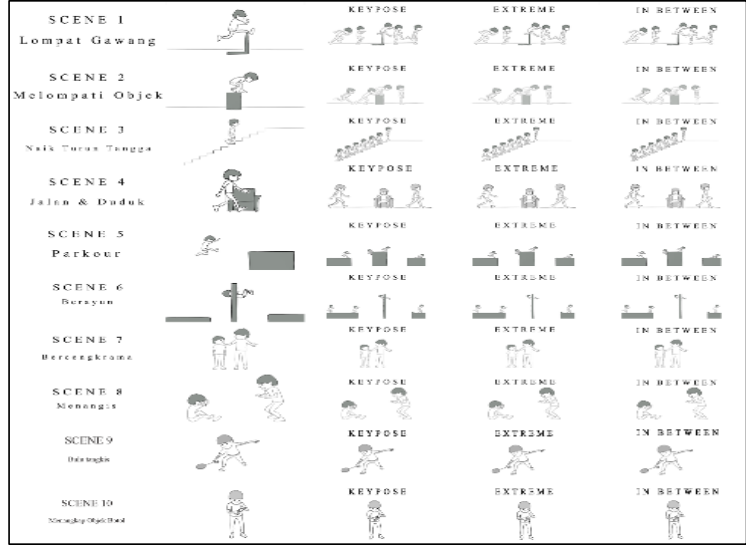

Gambar 3. Storyboard

\section{HASIL DAN PEMBAHASAN}

A. Tahap Produksi

- $\quad$ Modeling

Proses modeling dalam pembuatan video animasi 3 dimensi tentang gerakan manusia pada awalnya adalah menggunakan objek dasar cube, objek ini akan muncul saat pertama kali menjalankan program Blender atau menggunakan objek dasar lain dengan shortcut shift+ A, lalu memilih Mesh dan dilanjutkan dengan objek tertentu sesuai kebutuhan. Untuk merubah bentuk dari suatu objek dasar ke bentuk lainnya dilakukan dengan beberapa pengoperasian dasar pada Blender, seperti Grab untuk menggeser atau manarik objek, Rotate untuk memutar objek, dan Scale untuk mengubah ukuran objek. Merubah bentuk objek hanya dapat dilakukan pada edit mode sehingga membentuk objek figur manusia seperti pada gambar 4 dan objek lingkungan seperti pada gambar 5 .

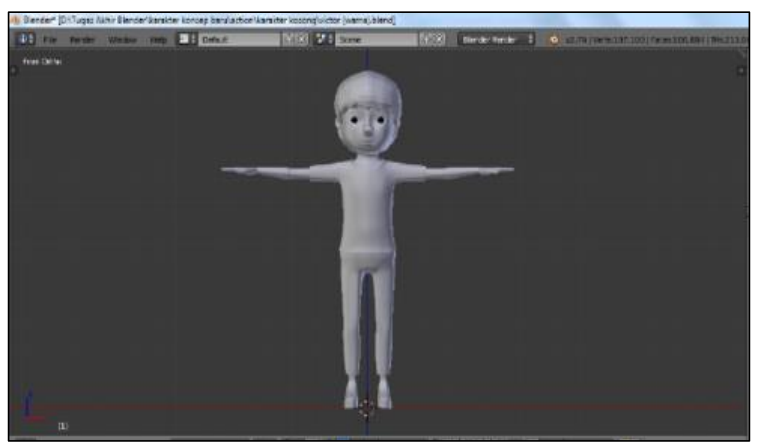

Gambar 4. Modeling Objek Figur 


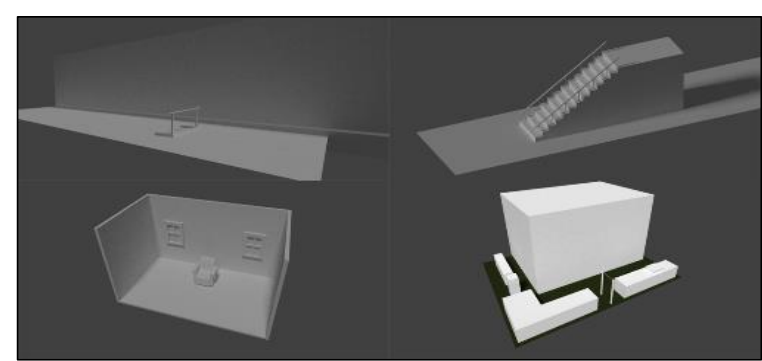

Gambar 5. Modeling Objek Lingkungan

\section{- $\quad$ Texturing}

Dalam tahap texturing beberapa model yang sudah dibuat sebelumnya akan diberi warna menggunakan material tools, untuk penambahan tekstur dilakukan dengan UV map, texturing pada objek figur manusia dapat dilihat pada gambar 6 dan objek lingkungan seperti tangga, sofa, dan lain sebagainya dapat dilihat pada gambar 7 .

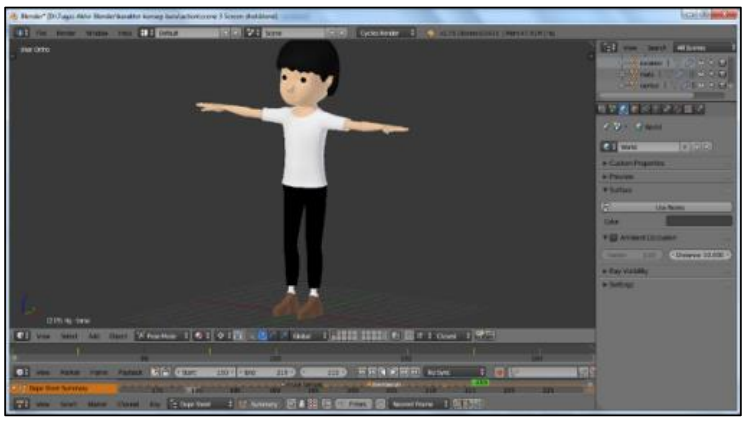

Gambar 6. Texturing Objek Figur

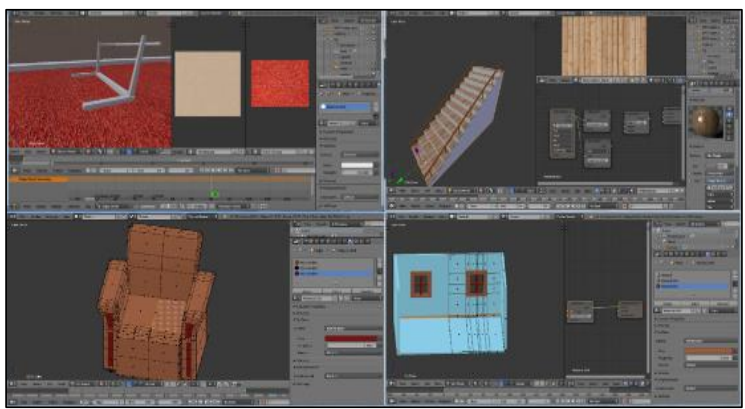

Gambar 7. Texturing Objek Lingkungan

- $\quad$ Rigging

Tujuan dari proses ini adalah untuk memberi tulang pada model 3D untuk mempermudah proses pemberian pose. proses rigging figur manusia yang menggunakan armature Human (Meta-rig) seperti yang diperlihatkan pada gambar 8. Hasil dari rigging adalah membentuk rangkaian controller yang akan digunakan animator untuk mengatur pose.

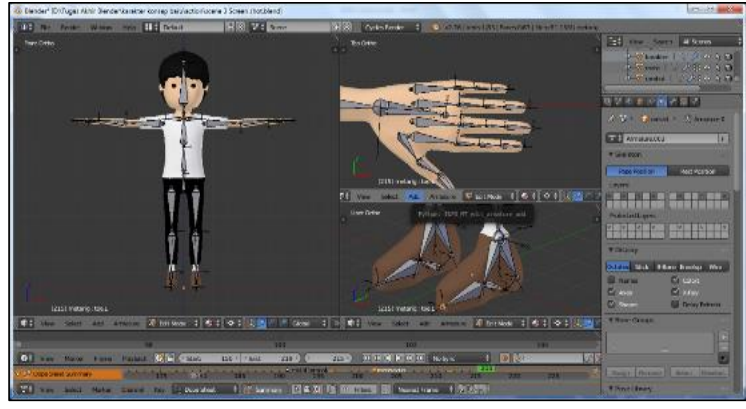

Gambar 8. Rigging Objek Figur

\section{- $\quad$ Animating}

Animating dimulai dengan menentukan keypose yang dibuat menurut storyboard, keypose atau pose kunci adalah rangkaian pose awal yang menunjukkan suatu gerakan tertentu. Pengaturan pose pada objek figur melalui controller yang telah dibuat pada tahap rigging. Gambar 9 adalah contoh keypose pada yang telah ditentukan untuk gerakan animasi pada scene 1 .

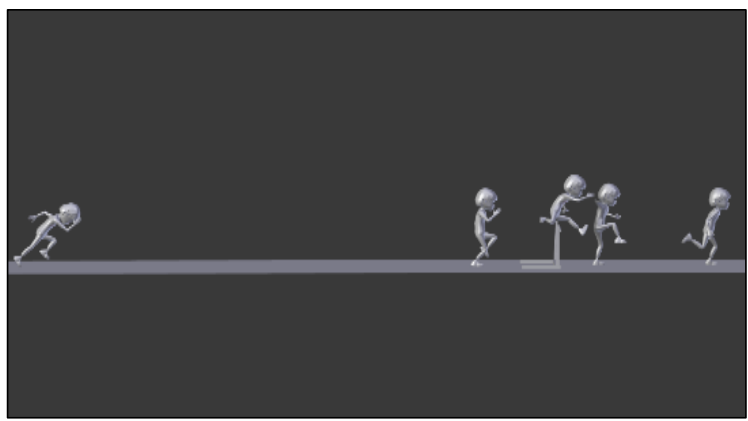

Gambar 9. Keypose

Setelah keypose ditentukan, selanjutnya adalah dengan menentukan extreme. Extreme adalah serangkaian pose yang dibuat untuk menunjukkan efek gerak animasi, walaupun belum menghasilkan suatu gerak animasi sepenuhnya. Gambar 10 adalah contoh extreme pada scene 1 .

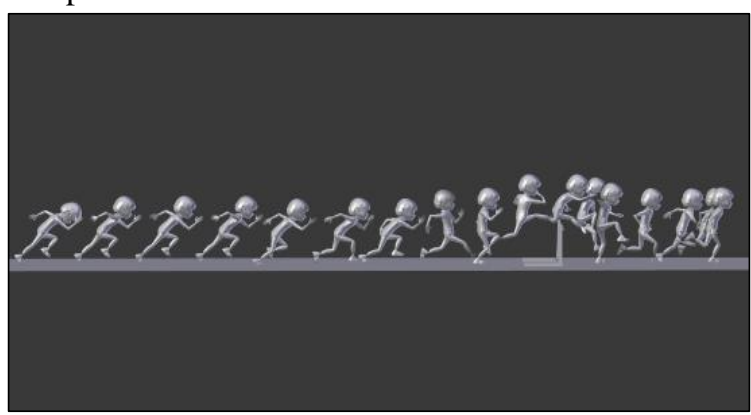

Gambar 10. Extreme 
Selanjutnya gerakan animasi diperhalus dengan pemberian in between diantara extreme yang sudah dibuat sebelumnya seperti yang ditunjukkan pada gambar 11.

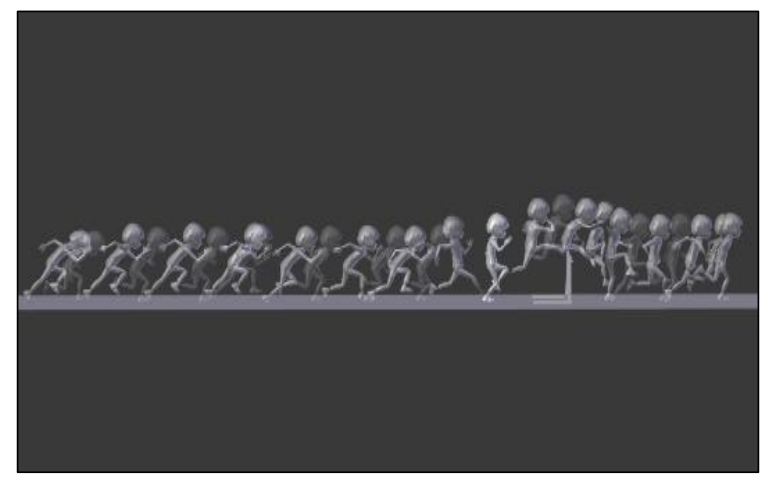

Gambar 11. In between

Pengujian animasi menggunakan tool motion path, tool ini akan menghasilkan garis yang merupakan alur gerak animasi pada suatu controller yang disertai dengan nomor keyframe berwarna oranye dimana posisi controller itu disimpan, pengujian dilakukan untuk mengetahui apakah gerak animasi sudah memenuhi prinsip arcs. Gambar 12 adalah keseluruhan pengujian prinsip arcs pada objek figur.

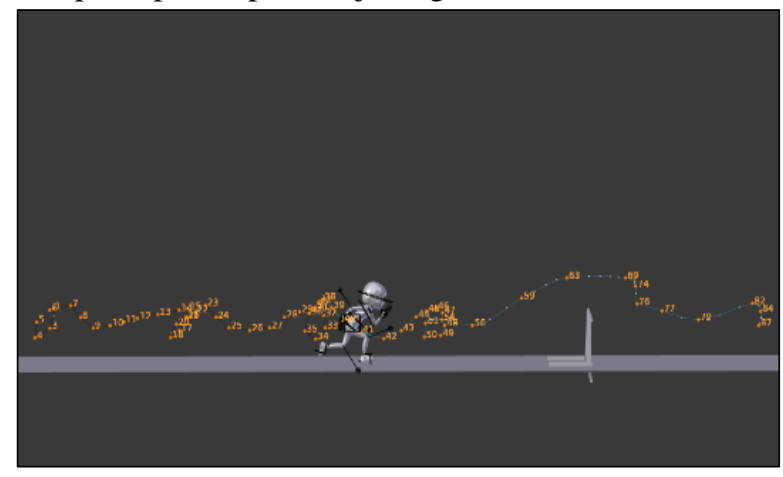

Gambar 12. Hasil Pengujian Animasi

\section{- $\quad$ Lighting}

Pencahayan atau lighting pada animasi 3 dimensi tentang gerakan manusia menggunakan objek plane dengan efek emission. Cahaya yang dihasilkan oleh efek emission tidak jatuh hanya pada satu titik saja melainkan cahayanya menyebar ke segala arah yang menghasilkan gambar yang lebih baik. Dibandingkan dengan penggunaan lamp pada Blender yang butuh beberapa objek lamp, penggunaan emission hanya membutuhkan beberapa objek dan pengaturannya hanya dilakukan pada kekuatan cahaya atau energy, Gambar 13 adalah contoh penggunaan emission untuk proses lighting.

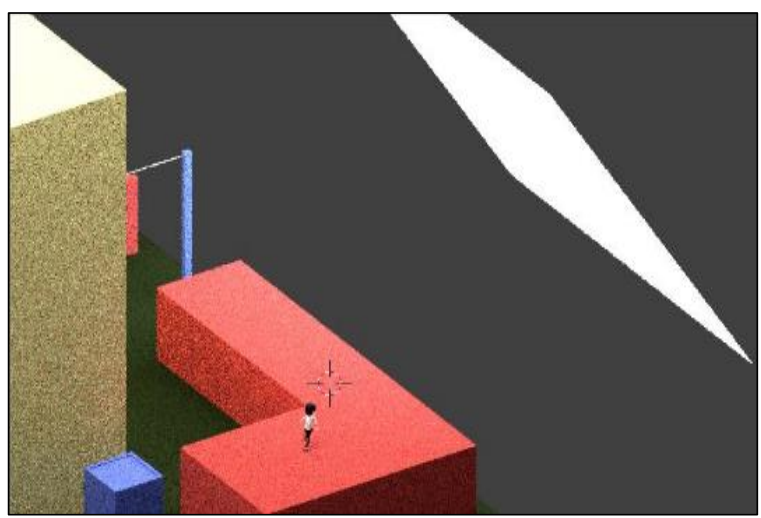

Gambar 13. Hasil Lighting Menggunakan Emission

- Camera Operation

Pemberian camera bertujuan untuk menampilkan hasil render gambar. Tahapan ini dilakukan dengan mengatur jenis dan sudut pandangan pengambilan gambar oleh camera seperti pada gambar 14 .

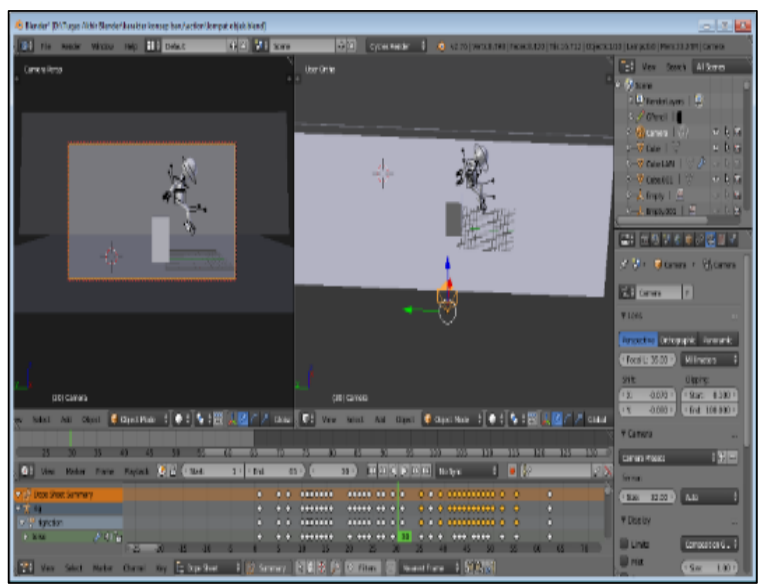

Gambar 14. Pengaturan Sudut Pandang Camera

\section{- $\quad$ Rendering}

Proses rendering dilakukan dengan memilih render engine yang akan digunakan. Seperti yang dilihat pada gambar 15 Blender memiliki tiga jenis render engine, yaitu Blender Render, Blender Game, dan Cycles Render. Proses rendering animasi 3 dimensi tentang gerakan manusia menggunakan engine Cycles Render karena hasil pencitraan cahaya yang terlihat lebih baik. Terdapat tiga pilihan render pada Blender, antara lain Render yang digunakan hanya untuk menghasilkan sebuah file gambar, Animation yang digunakan untuk menghasilkan sebuah video animasi, dan Audio yang digunakan hanya untuk menghasilkan file format audio. 


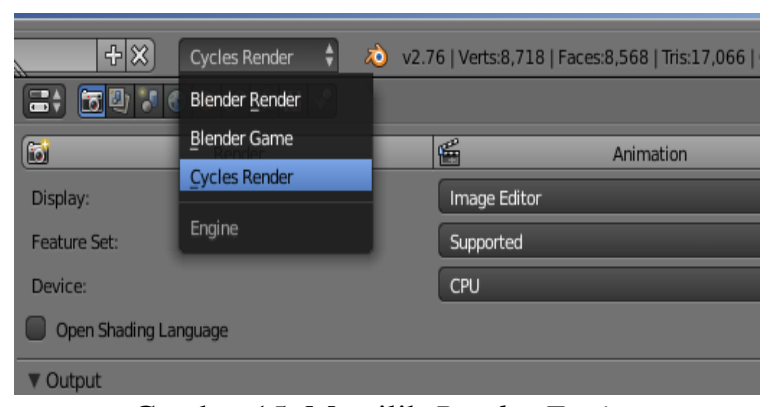

Gambar 15. Memilih Render Engine

Gambar 16 adalah hasil akhir dari proses rendering untuk animasi 3 dimensi tentang gerakan manusia yaitu output berupa video animasi berformat .MP4.

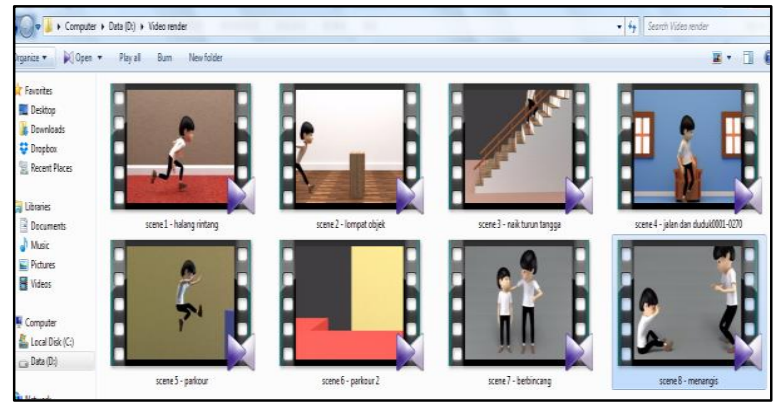

Gambar 16. Hasil Proses Rendering

\section{B. Tahap Pasca Produksi}

- $\quad$ Final Editing

Proses Final Editing menggunakan program Corel Video Studio Pro X6. Urutan hasil akhir video mengikuti urutan yang dijelaskan pada storyboard, yaitu dimulai dari scene 1 hingga scene 10. Dimulai dengan membuat folder project yang berguna untuk mengumpulkan materi untuk membuat video animasi 3D tentang gerakan manusia seperti pada gambar 17 .

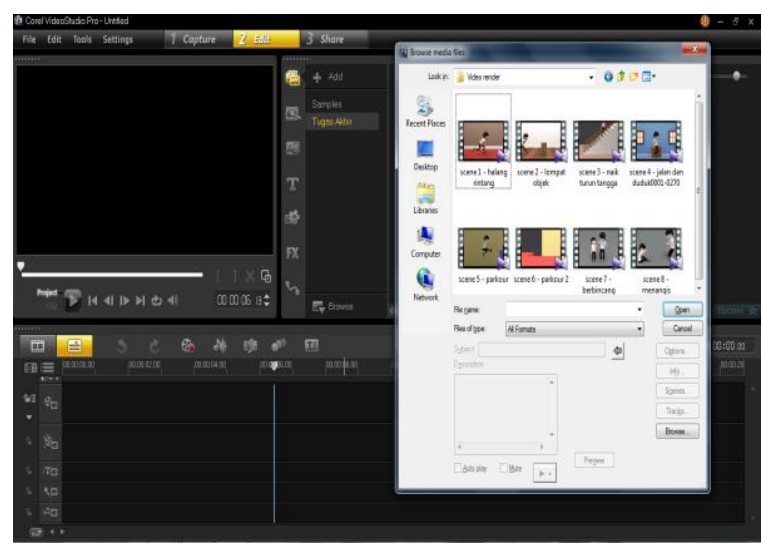

Gambar 17. Membuat Foder Project

Dalam proses editing, File-file tersebut digabungkan kedalam timeline seperti yang dilihat pada gambar 18 dan dilanjutkan dengan mengexport seluruh file menjadi sebuah video yang nantinya akan dirender.

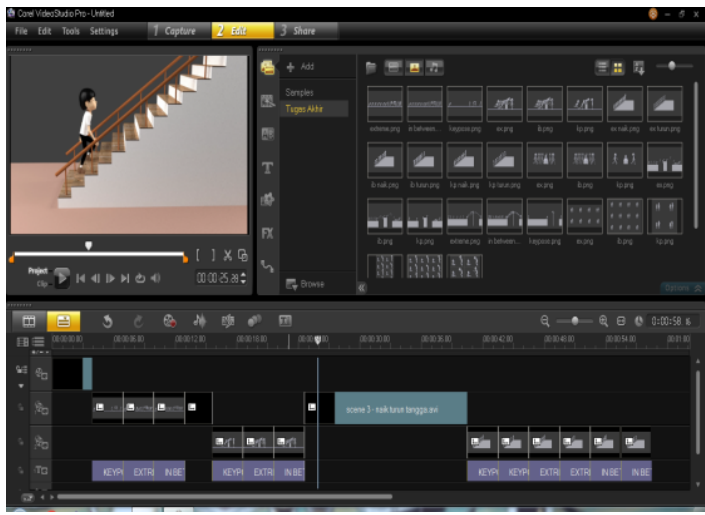

Gambar 18. Proses Final Editing

- $\quad$ Hasil Video Animasi

Gambar 19 adalah hasil akhir dari tahapan pasca produksi video animasi 3 dimensi tentang gerakan manusia dengan durasi sepanjang 3 menit 54 detik, dengan ukuran $229 \mathrm{MB}$, dan berformat MP4.

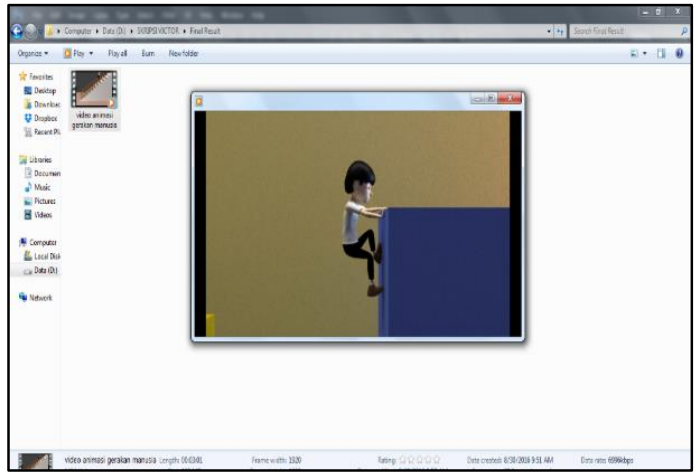

Gambar 19. Hasil Akhir Final Editing

\section{B. KESIMPULAN DAN SARAN}

\section{A. Kesimpulan}

Berdasarkan penelitian tentang Implementasi Gerakan Manusia pada Animasi 3D dengan Menggunakan Metode Pose to pose yang sudah diselesaikan, maka kesimpulan yang didapatkan pada penelitian ini adalah sebagai berikut: 
1. Penelitian ini menghasilkan video animasi 3D mengenai gerakan manusia dengan kualitas gerak animasi yang terkesan nyata dan halus.

2. Video animasi dibuat menggunakan metode pose to pose pada proses animating.

3. Seluruh gerak animasi yang telah dihasilkan juga sudah memenuhi prinsip arcs sebagai salah satu prinsip animasi.

4. Keypose dibuat untuk mengkonsepkan gerak animasi pada figur, extreme berfungsi untuk memberi efek animasi itu sendiri, dan in between berfungsi untuk menyempurnakan sebuah gerak animasi.

\section{B. Saran}

Adapun beberapa saran yang perlu dipertimbangkan untuk pengembangan lanjut pada penelitian ini maupun penelitian dengan topik yang sama, antara lain :

1. Sangat penting untuk menyesuaikan spesifikasi perangkat keras yang akan digunakan dengan kebutuhan pada program Blender. Hal ini bertujuan agar penggunaan program Blender dapat lebih optimal.

2. Gunakan video referensi agar mempermudah menentukan pose pada sebuah gerakan.

3. Kualitas gerak animasi tidak hanya dengan memahami metode penganimasiannya saja, namun prinsip-prinsip animasi juga perlu dipahami dan diterapkan.

\section{DAFTAR PUSTAKA}

[1] Beane Andy, 3D Animation Essentials, Indianapolis: John Wiley and Sons, Inc. 2012.

[2] Chan K. 2007. "A Proposed Character Animation Workflow For Digital production Arts With Preparation For Cloth Dynamics", Clemson University. Clemson, South Carolina, 2007.

[3] Hendratman, Hendi. The Magic Of Blender 3D Modeling. Bandung: Informatika. 2015.

[4] Raymond Francis. (2013, Jan.15). Introducing Corel VideoStudio Pro [online]. Available: www.corel.com/User_Guide_EN\&usg=AFQjCNEII0p7XLX fz1O4IjWpWtkNH0zwQ\&sig2=HFANja_Ew5I05spCcyGJ_ Q\&cad=rja,23.

[5] Marfil Rompas, Alicia Sinsuw, Jimmy Robot, Xaverius Najoan. "Perancangan Gedung Fakultas Teknik Unsrat dengan Perspektif 3D”. Jurnal Teknik Informatika Unsrat Vol. 2 No. 2. ISSN: 2301-8364, Aug 2013.

[6] Oetomo S.P, Sutejo Aris. "Film Animasi Sejarah Penyobekan Bendera di Hotel Yamato". Jurnal Createvitas Vol. 2, No 2, pp.237-240, Jul 2013.

[7] Priyatmono, Dody. (2013, Aug 29) Proses Pemuatan Karya Animasi[online]. Available: http : // www.dodyanimation. com / 2013 /08/29/proses-pemuatan-karya-animasi/\#more1056.

[8] Putra, M.S.A.D. "Pembuatan Aplikasi Model 3D Interaktif Menggunakan Blender (Studi Kasus: Gedung STMIK
AMIKOM Yogyakarta)". Sekolah Tinggi Manajemen Informatika dan Komputer AMIKOM., Yogyakarta. 2014.

[9] Sukintaka. Teori Pendidikan Jasmani (Filosofi, Pembelajaran dan Masa Depan). Bandung: Penerbit Nuansa. 2004.

[10] Suratinoyo, H.S. "Cerita Rakyat Daerah Minahasa : Implementasi Short Film Animasi 3D”. E-jurnal Teknik Informatika Universitas Sam Ratulangi Universitas Sam Ratulangi. Vol 2, No 2. Oct 2013

[11] Williams, Richard. The Animator's Survival Kit: A Manual of Methods, Principles, and Formulas for Classical, Computer, Games, Stop Motion, and Internet Animators. London: Faber and Faber, 2002

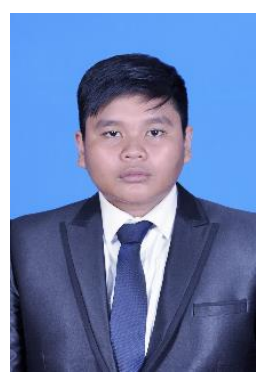

Sekilas dari penulis dengan nama lengkap Victor Waeo, lahir di Balikpapan, Provinsi Kalimantan Timur. Anak pertama dari 2 bersaudara. Dengan pendidikan Sekolah Dasar Negeri 13 Wanasari. Kemudian melanjutkan ke Sekolah Menengah Pertama Negeri 1 Cikarang Barat. Kemudian melanjutkan ke Sekolah Menengah Atas SMAN 2 Tambun Selatan. Setelah lulus tahun 2011 melanjutkan ke Perguruan Tinggi di Universitas Sam Ratulangi dengan mengambil Jurusan Teknik Informatika. Pada Tahun 2015 bulan juli, penulis membuat Skripsi demi memenuhi syarat Sarjana (S1) dengan penelitian berjudul Implementasi Gerakan Manusia Pada Animasi 3D dengan Menggunakan Metode Pose to Pose yang dibimbing oleh dua dosen pembimbing yaitu Arie S.M. Lumenta, ST., MT dan Brave A. Sugiarso, ST., MT sehingga pada tanggal 29 November 2016 penulis resmi lulus di Teknik Informatika Universitas Sam Ratulangi Manado dan menyandang gelar Sarjana Komputer dengan predikat Sangat Memuaskan. 